\title{
A LEITURA E OS CANAIS INTERMEDIÁRIOS DE INFORMAÇÃO NA FORMAÇÃO CONTINUADA DE PROFESSORES UNIVERSITÁRIOS
}

\author{
Dulcinéa Sarmento Rosemberg - rosember@npd.ufes.br \\ Mestre em Educação pelo Programa de Pós-Graduação em Educação \\ Universidade Federal do Espírito Santo - UFES. \\ Professora do Curso de Biblioteconomia, Depto. de Ciência da Informação, \\ Universidade Federal do Espírito Santo - UFES.
}

\begin{abstract}
Resumo
Apresenta a leitura como o canal de informação mais utilizado pelos professores universitários, bem como discute o papel dos canais intermediários de informação no seu processo de formação continuada.

Palavras-Chave: leitura; professor universitário; canais de informação; formação continuada

Abstract

This article discusses the role of intermediate information channels in continuing education, and shows that reading is the most frequently used information channel of college and university lectures.
\end{abstract}

Keywords: University lectures, intermediate information channels, Access and use of information, Continuing education.

\section{INTRODUÇÃO}

Nas últimas décadas, o mundo transformou-se de maneira ampla e profunda. Essas transformações, de natureza científica, tecnológica, política, econômica, social e cultural, têm-nos levado a enfrentar sucessivos e complexos acontecimentos que modificam as nossas vidas nos mais diversos aspectos. Alguns desses acontecimentos estão relacionados com as funções sociais e econômicas que a informação e o conhecimento têm ocupado na sociedade, bem como com os avanços das telecomunicações e da informática (telemática), que têm facilitado a produção e a circulação de grandes volumes de informação. Esses são fatos que requerem das instituições e dos profissionais adequação e atualização constantes, visando ao acompanhamento do "estado da arte" das suas áreas de conhecimento.

Atualmente, em face das funções que tradicionalmente lhes têm sido imputadas, as universidades talvez sejam as instituições mais chamadas pela sociedade a acompanhar as transformações da vida humana. Considerando que esse acompanhamento requer uma participação efetiva das universidades na sociedade e que as instituições são representadas 
socialmente pelos seres humanos, os professores atuantes nas instituições universitárias do nosso tempo tornam-se agentes diretamente responsáveis pelo atendimento a esse chamado.

Sabendo-se que as instituições são produtos das ações humanas, podemos afirmar que tanto a integração das universidades com a sociedade quanto o nível de inovação que delas esperamos, o qual deve caracterizá-las como instituições que estão sempre à frente do seu tempo, dependem sobremaneira da atuação de um dos seus segmentos mais importantes - os professores universitários. Esses, por sua vez, apoiados em políticas educacionais pertinentes, devem estar se apropriando permanentemente do conhecimento produzido com vistas à objetivação desse mesmo conhecimento, mediante as funções de Ensino, Pesquisa e Extensão, em consonância com as exigências sociais do hoje e do amanhã.

Em seus constantes esforços para produzir e/ou para disseminar conhecimentos, obter e manter intercâmbio de informações com a comunidade científica, os pesquisadores entram em contato com dois subsistemas básicos de comunicação - o formal e o informal (Prazeres, 1989). Hoje, os canais de informação que compõem esses subsistemas são múltiplos e bastante diversificados, devido aos avanços, principalmente, nas áreas da informática e das telecomunicações. Esses canais variam consideravelmente quanto ao grau de eficiência e extensão da clientela e são usualmente classificados como canais formais, semiformais, informais e intermediários.

Os canais formais são compostos das fontes de informação impressas, tais como livros, publicações periódicas, enciclopédias, dicionários, revisões de literatura, anuários, bibliografias, periódicos de indexação e resumos, índices, bibliografias de bibliografias e outros. Os canais semiformais incluem pré-publicações, tais como teses de doutorado, dissertações de mestrado, relatórios técnicos, relatórios de pesquisas, cópias de comunicações orais, trabalhos e/ou resumos apresentados e/ou publicados em anais de reuniões acadêmicocientíficas. Os canais informais são compostos das comunicações interpessoais entre pares, efetuadas em conferências, congressos, seminários, simpósios e similares e, mais recentemente, das comunicações trocadas mediante a utilização de redes de computadores, tais como a INTERNET (grupos de discussão, e-mails e chats). Atualmente, facilitados pelos avanços da telemática, grupos de indivíduos, com freqüência, bastante distanciados geograficamente, trocam correspondências e notícias sobre pesquisas e publicações, 
instituindo entre si uma verdadeira rede de intercâmbio de informações, caracterizando o que comumente é denominado de colégio invisível.

Os canais intermediários, por sua vez, são representados pelas instituições responsáveis pela preservação, organização e disseminação da informação registrada (canais formais e semiformais), bem como pelo papel de facilitadoras da busca e da recuperação de informações onde quer que estejam física ou virtualmente armazenadas. Dentre essas instituições, destacam-se as bibliotecas, os arquivos, os centros de documentação e informação, os centros de análises de informações, os centros referenciais e outras.

Com base nesta tipologia, realizamos uma pesquisa que, entre outros, teve como objetivo identificar os canais mais utilizados pelos professores da Universidade Federal do Espírito Santo - UFES, para buscar e recuperar informações técnico-científicas e pedagógicas necessárias ao desenvolvimento da sua formação contínua.

Para efeito deste estudo, buscaremos apresentar os resultados da pesquisa que permitem destacar a leitura como o canal de informação mais utilizado e, conseqüentemente, discutir o papel dos canais intermediários no processo de formação continuada de docentes universitários.

Realizamos um estudo quanti-qualitativo, coletando os dados mediante a aplicação de questionários a $21 \%$ dos 777 docentes especialistas, mestres e doutores, em efetivo exercício, em regime de dedicação exclusiva, lotados em cada um dos nove Centros que compõem a estrutura da UFES. Assim, numa perspectiva sócio-histórica, adotamos o tipo de pesquisa denominado exploratório-descritivo e utilizamos o método histórico-dialético como princípio metodológico para a condução do trabalho investigativo.

\section{ACESSANDO A LEITURA MEDIANTE OS CANAIS INTERME- DIÁRIOS DE INFORMAÇÃ̃?}

Apresentamos aos professores diversos tipos de canais, solicitando que indicassem os três principais utilizados para adquirir informação recente na sua área de atuação. Conforme nos mostra a Figura 1, os respondentes utilizam com maior freqüência a leitura $(95,7 \%)$, os eventos técnico-científicos $(84,1 \%)$, as redes de computadores $(42,7 \%)$, conversas com colegas da área (40,2\%), cursos de aperfeiçoamento (32,9\%), visitas técnicas $(20,7 \%)$ e outros canais $(11,6 \%)$, tais como contatos com fornecedores de equipamentos e serviços, 
livrarias, contatos com o mercado de trabalho mediante palestras e projetos de extensão, pesquisas bibliográficas, orientação de alunos que dividem conhecimento sobre o "estado da arte", desafios da própria área de atuação, intercâmbio com pesquisadores no País e no exterior, associações profissionais, conversas com profissionais que atuam no mercado de trabalho, projetos de extensão e de pesquisa, viagens de estudos e pesquisa empírica.

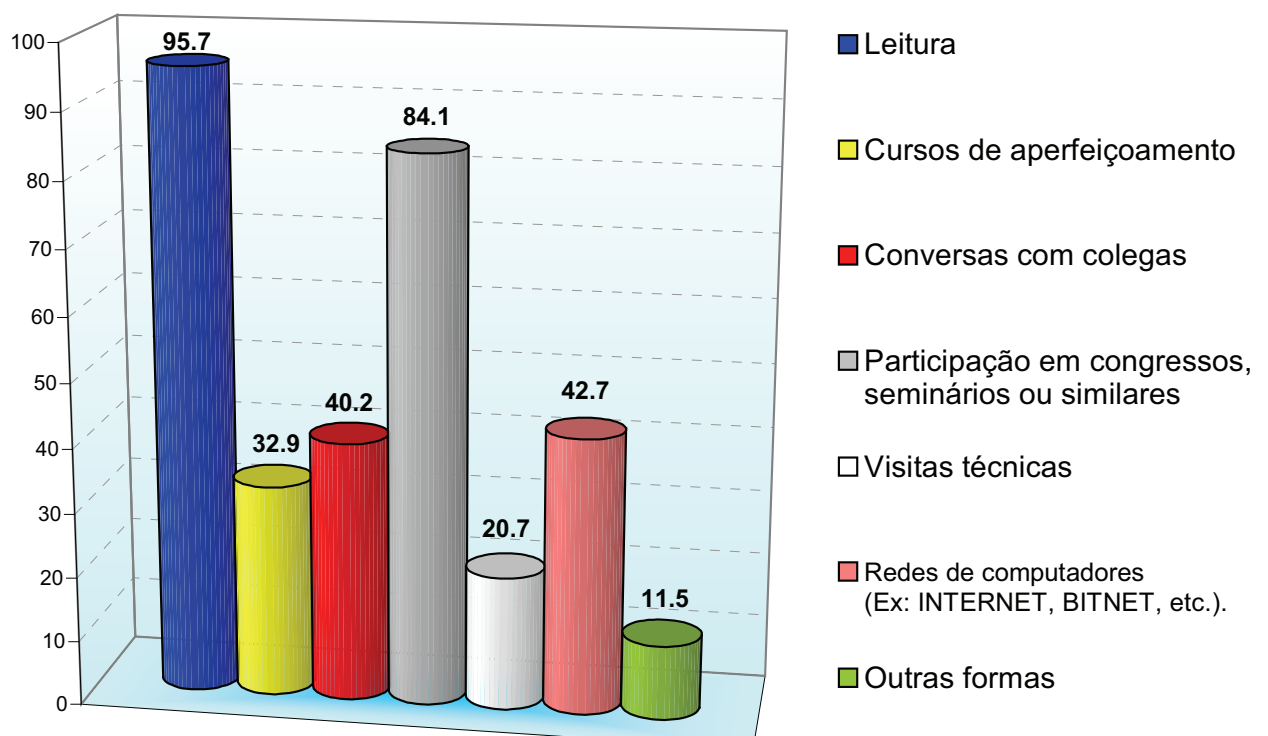

Figura 1 - Canais de Informação

$\mathrm{Na}$ trajetória percorrida desde as sociedades primitivas até as atuais, foram construídas centenas de formas de conceber o ato de ler e inúmeras foram as práticas e modalidades de leitura instituídas socialmente em cada época (Cavalo \& Chartier, 1998).

Entre as várias concepções, práticas e modalidades de leitura historicamente concebidas pelas sociedades, destaca-se a leitura vinculada à educação do ser humano, sistemática ou assistemática, envolvendo sempre dois fatores fundamentais: formação e informação (Silva, 1995). Para o autor, seria quase que impossível imaginar um sistema educacional no qual a leitura não estivesse presente, porque a obra escrita, além de informar, também cumpre objetivos de formação inicial e continuada, tendo em vista que, ao mesmo tempo que "... coloca ao leitor as atitudes, valores, crenças, etc ... instituídos socialmente" (Silva, 1995, p. 35), pode ainda possibilitar a reflexão sobre essas mesmas formas instituídas por ele no curso da sua própria história.

Nesse cenário, a leitura tornou-se um canal de comunicação tradicionalmente sedimentado, que pode permitir ao homem um encontro tanto consigo mesmo quanto com a própria realidade sociocultural na qual está inserido. $\mathrm{O}$ livro ou qualquer outro tipo de material escrito pode levar, nesse sentido, o ser humano a uma imersão no processo histórico, e daí ser sempre a leitura “... encarnação de uma intencionalidade” que reflete sempre o humano (Silva, 1995, p. 41). 
Como indicamos, a leitura na UFES foi considerada por $95,7 \%$ dos professores como o meio mais utilizado para fins formativos. Isso nos permite correlacioná-la com o acesso via canais formais, semiformais e intermediários.

As informações que originam os formatos documentais apresentam-se em suportes que variam desde o papel e o cd rom até a sua disponibilidade on line, encontrando-se armazenados em bibliotecas tradicionais e virtuais as quais permitem diariamente o livre acesso aos usuários. Sendo assim e cientes do fato de que a maioria das fontes bibliográficas citadas, ao serem disseminadas, permitem a formação das bibliotecas pessoais e institucionais, tradicionais e virtuais, solicitamos aos professores que indicassem a freqüência mensal com que utilizam os vários tipos de bibliotecas à sua disposição na atualidade.

A Universidade possui um Sistema Integrado de Bibliotecas (SIB/UFES) composto, formalmente, de três bibliotecas localizadas nos Campi de Goiabeiras, Maruípe (Centro Biomédico) e Alegre (Centro Agropecuário), e de diversas bibliotecas denominadas informais ou setoriais. Apesar de as bibliotecas dos Centros Biomédico e Agropecuário serem reconhecidas oficialmente como setoriais, neste estudo foram colocadas, apenas para efeito de análise de dados, no mesmo nível das bibliotecas informais.

Os resultados obtidos (Figura 2) evidenciaram que a Biblioteca Fernando de Castro Moraes, mais conhecida como Biblioteca Central da UFES, é freqüentada mensalmente pelos professores nos seguintes níveis: $\underline{\text { nunca - }}$ $30,5 \% ; \underline{1-2 \text { vezes }}-31,7 \%$; $2-4$ vezes $-8,5 \%$; $4-8$ vezes $-6,1 \%$ e mais de 8 vezes $-3,7 \%$ num universo em que $19,5 \%$ dos sujeitos preferiram não responder à questão.

As informações dos professores dos cursos (Pedagogia, Física, Matemática, Artes Plásticas, Economia, Serviço Social, Educação Física, Ciência da Computação, Letras, História, Psicologia, Engenharia Elétrica, Odontologia, Ciências Fisiológicas, Biologia, entre outros) em que existem Bibliotecas Setoriais permitiram verificar os seguintes percentuais de freqüência mensal: $\underline{\text { nunca }}-12,8 \% ; \underline{1-2 \text { vezes }}-29,9 \% ; \underline{2-4}$ vezes $-(15,9 \%) ; \underline{4-8 \text { vezes }}$ $-11,6 \%$ e mais de 8 vezes $-7,9 \%$.

Para 15,9\% dos professores, uㅡca foi necessário buscar informações em bibliotecas localizadas em outras instituições, mas para $28 \%$ isso foi necessário pelo menos de $\underline{1-2}$ vezes durante o mês. Proporcionalmente, pudemos verificar que, na escala de $\underline{2-4}$ e de $\underline{4-8}$ vezes, tendem a freqüentar mensalmente a Biblioteca de outras instituições em torno de $6,1 \%$ e $4,3 \%$, respectivamente, enquanto $5,5 \%$ deles dizem recorrer a elas mais de $\underline{8}$ vezes por mês.

Analisando os percentuais da Figura 2 no que tange à utilização de biblioteca particular e comparando-os com os percentuais de freqüência a outros tipos de bibliotecas, observamos um pequeno aumento do percentual - 27 ,

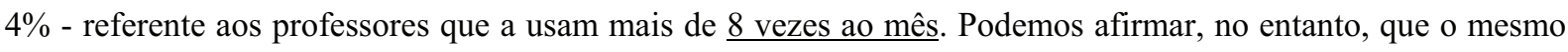
ainda não é expressivo, tendo em vista a baixa freqüência às outras bibliotecas.

Em relação à freqüência às bibliotecas virtuais, disponíveis para consulta especialmente via INTERNET entre outras redes de computadores, pudemos inferir, ao compará-la com os índices de freqüências às bibliotecas 
tradicionais, que o seu uso pelos professores também não é muito significativo diante das facilidades que esse tipo de biblioteca pode apresentar para o desenvolvimento do processo de busca e recuperação da informação corrente. Essa afirmativa encontra ressonância, principalmente em relação aos 34,2\% dos professores que, ao não responderem à questão, podem estar revelando que também não as utilizam com freqüência. Contudo, quando tomamos o índice de $11,6 \%$ referente ao número de professores que as freqüentam mais de $\underline{8 \text { vezes ao }}$ mês, percebemos que, depois das bibliotecas particulares $(27,4 \%)$, este é o canal intermediário mais utilizado para buscar informação atualizada.

Os resultados obtidos sobre a utilização das bibliotecas dos colegas igualmente são relativamente baixos diante da importância atribuída à leitura e dos índices de freqüências às demais bibliotecas, bem como pela relevância do intercâmbio de informações entre os próprios pares no âmbito da Instituição. Os respondentes freqüentam mensalmente a biblioteca do colega $1-2$ vezes $-22 \%$; 2-4 vezes $-6,7 \%$; $4-8$ vezes $-3 \%$ e mais de 8 vezes por mês $-6,1 \%$. Entretanto, $20,7 \%$ deles, ou seja, quase o mesmo percentual dos que as utilizam 1-2 vezes no mês, dizem que nunca necessitam das bibliotecas dos colegas.

Esses dados evidenciam, portanto, que a Biblioteca Central da Instituição se destaca dentre os outros tipos de bibliotecas em dois momentos: como aquela que nunca é freqüentada mensalmente $(30,5 \%)$ e como a mais freqüentada pelo menos de $1-2$ vezes por mês $(31,7 \%)$. Verificamos também que na mesma medida em que aumenta a freqüência mensal aos outros tipos de bibliotecas diminui a freqüência do professor à Biblioteca Central.

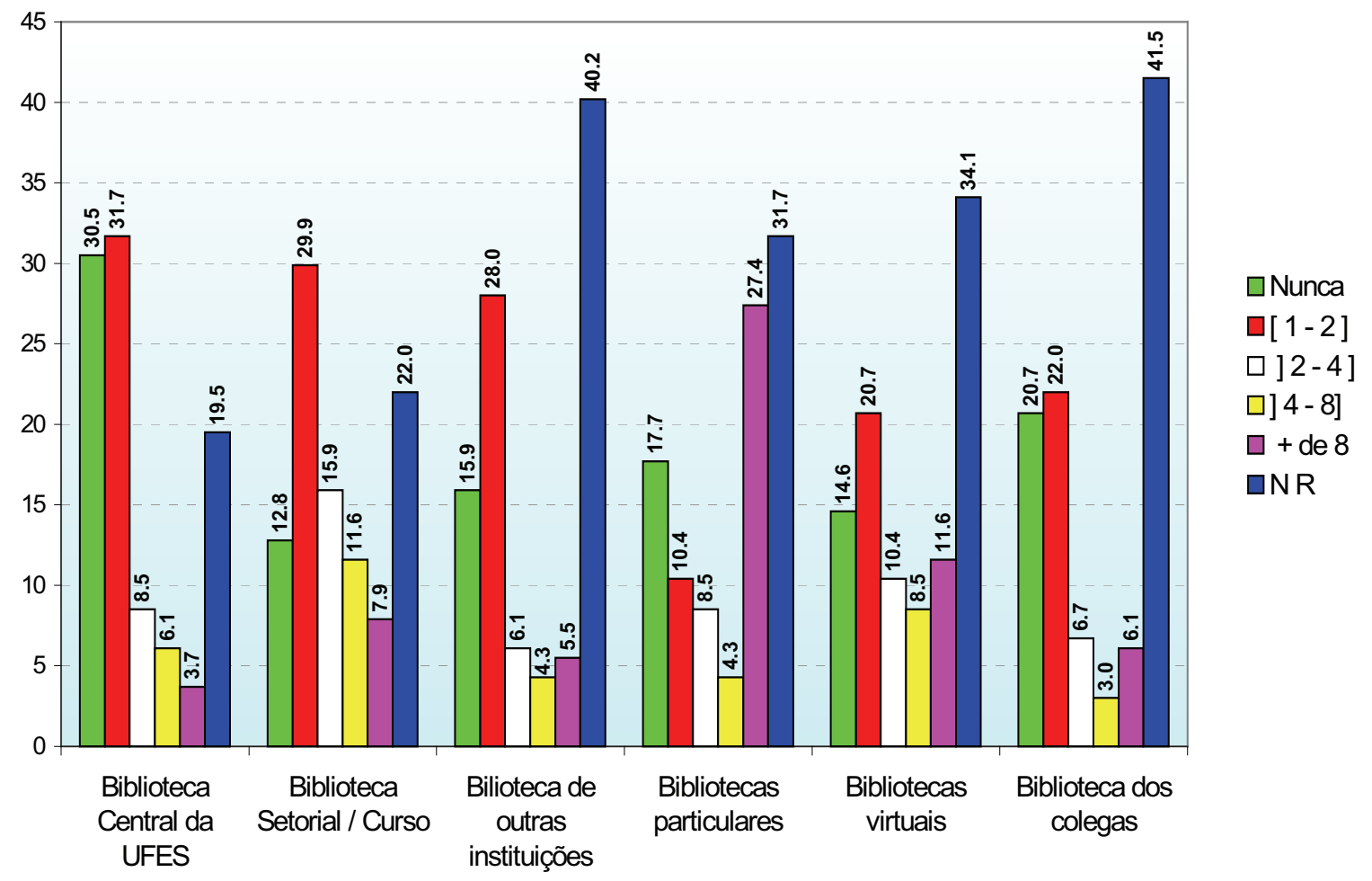

Figura 2 - Freqüência Mensal de Utilização de Bibliotecas 
Em razão do destaque dado à leitura como o canal mais utilizado pelos docentes durante o processo de formação continuada é necessário destacar que estes índices são relativamente baixos, de um lado por colocarem em suspensão o papel que as bibliotecas deveriam representar no cenário da formação do professor e, de outro, por revelarem uma certa contradição nas falas dos professores que dizem ler para se atualizar. Se não freqüentam as bibliotecas tradicionais e virtuais, se não trocam fontes bibliográficas com os colegas, se não usam a sua própria biblioteca mais de 8 vezes ao mês, então, como a leitura pode ser o canal de informação mais utilizado durante a ocorrência do processo de formação continuada? E, ainda, evidenciada a baixa freqüência dos professores às bibliotecas Central e Setoriais, como devem ser interpretados os dados fornecidos acerca da avaliação de suas coleções quanto à atualização?

De acordo com Barbosa (1997), o estudo de necessidades e usos de informações tem gerado inúmeros trabalhos conceituais e empíricos que, não raramente, destacam os fatores facilitadores e dificultadores que, na opinião dos usuários, interferem na freqüência de uso, bem como no valor e na utilidade das unidades de informação. Um dos fatores citados na literatura o qual pode influenciar nessa freqüência é o nível de atualização da coleção das bibliotecas.

Diante dessa constatação, julgamos pertinente solicitar aos docentes que opinassem sobre o grau de atualização das coleções das Biblioteca Central e Setoriais existentes na Universidade. A esse respeito, observando a Figura 3, verificamos que a coleção da Biblioteca Central é regular para 33,5\% dos docentes consultados; é boa para $9,8 \%$ e é sofrível e ruim para $29,5 \%$ dos respondentes. Não emitiram nenhuma opinião e preferiram não responder à questão $12,2 \%$ e $14,6 \%$, respectivamente. Num universo em que $19,5 \%$ responderam que no seu curso não existe Biblioteca Setorial e em que 9,8\% não responderam à questão, os professores que têm à sua disposição esse tipo de biblioteca avaliam as suas coleções assim: 29,3\% acham regular; $11 \%$, boa; 25,6\%, sofrível/ruim e 4,9\% não têm opinião sobre o nível de atualização da coleção.

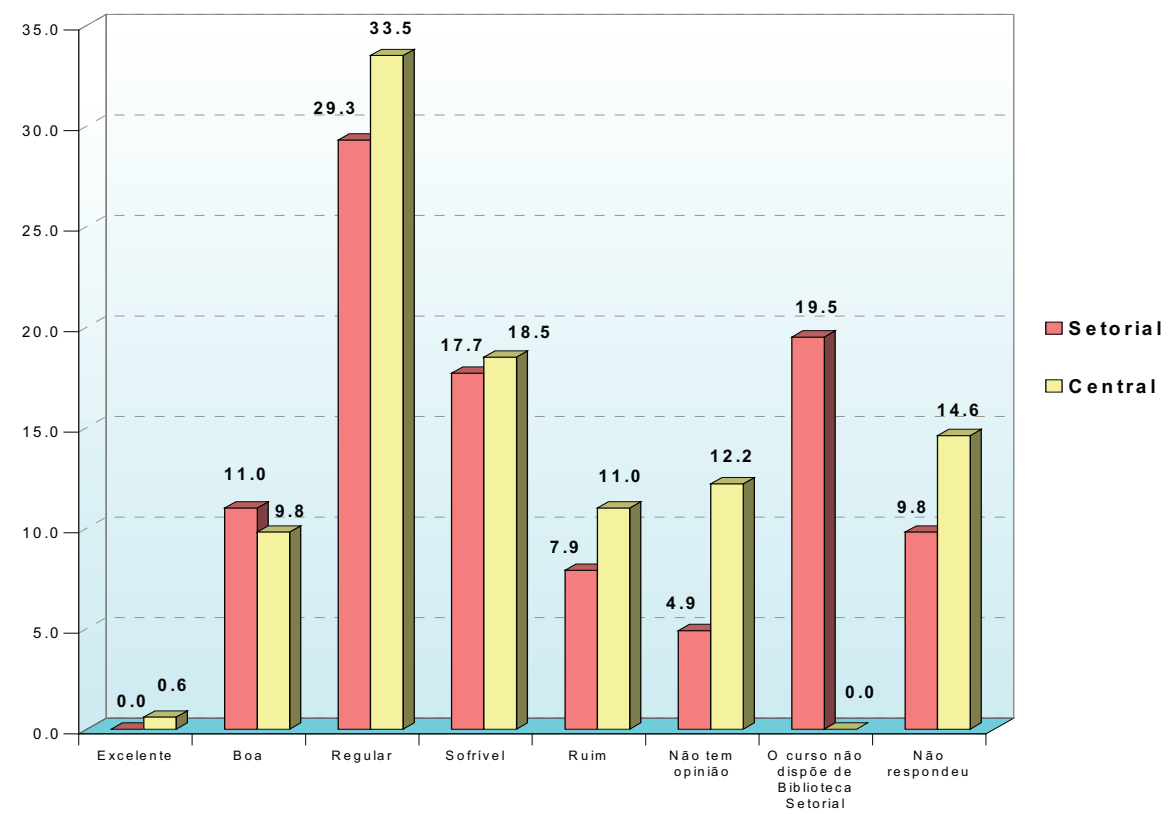

Figura 3 - Avaliação das Bibliotecas da UFES quanto à Atualização das Coleções 
Dumans et al. (1991) desenvolveram uma pesquisa visando obter informações sobre o comportamento informacional dos professores do Centro Pedagógico/UFES. As pesquisadoras constataram que, dos 34 professores que responderam aos questionários, 35\% informaram que o meio mais utilizado para buscar informações era procurar outra pessoa; 27,5\% buscar seu acervo particular; 25\% era consultar as bibliotecas da Universidade; e os outros $12,5 \%$ era procurar as bibliotecas de outras instituições para obterem a informação desejada. Quanto à freqüência às bibliotecas da Universidade, verificaram, ainda, que estas somente eram visitadas mensalmente, apenas uma vez, por 29,41\% dos professores (percentual igual não respondeu à pergunta); trimestralmente, uma vez, por $23,52 \%$; e anualmente, uma vez, por $8,82 \%$ dos professores.

Finalizando o estudo, após a análise desses e de outros dados coletados, as pesquisadoras concluíram que a biblioteca universitária “... parece não desempenhar um papel importante no desenvolvimento de pesquisas na área de educação no âmbito da Instituição, tendo em vista que a maioria dos professores não freqüenta a biblioteca e quando o faz não encontra a informação desejada" (Dumans et al., 1991, p. 5). Concluímos diante disso que os resultados obtidos no nosso estudo corroboram os resultados também obtidos pelas pesquisadoras referenciadas.

Posto isto, voltemos aos questionamentos anteriores sobre como devem ser interpretadas as informações coletadas no decorrer da nossa investigação a respeito da freqüência quanto ao uso das bibliotecas e da opinião dos usuários quanto à atualização das coleções. A baixa freqüência dos usuários a diferentes tipos de bibliotecas, incluindo-se aquelas existentes na Universidade, se comparada com os baixos percentuais de professores que dizem ser a política de bibliotecas da UFES um fator que dificulta muito (29,9\%), pouco (27,4\%) ou não dificulta de nenhuma forma $(20,1 \%)$ o seu processo de formação continuada, permite-nos inferir que não é a suposta falta de atualização das coleções das bibliotecas que fazem com que eles não as freqüentem.

Os dados evidenciam que outros estudos devem ser realizados, objetivando investigar de forma mais específica as incoerências aqui detectadas com relação ao destaque da leitura como o canal de informação mais utilizado no processo de formação continuada e à baixa freqüência aos variados tipos de bibliotecas, inclusive, o baixo uso da própria coleção particular (Figura 2). Por outro lado, é preciso ressaltar que, se a insatisfação dos professores com o nível de atualização das bibliotecas e com a política de bibliotecas estivesse ocasionando a baixa freqüência às mesmas, a tendência seria o aumento natural do índice de freqüência aos demais tipos de bibliotecas, o que na verdade não ocorre.

\section{CONSIDERAÇÕES FINAIS}

Diante da importância atribuída pelos professores à leitura no contexto da sua formação continuada e por serem historicamente as bibliotecas tradicionais e, mais recentemente, as virtuais as principais instituições intermediárias do processo de busca e recuperação da informação registrada, portanto, passíveis de promover o acesso à leitura em quaisquer suportes informacionais, torna-se imprescindível que professores e bibliotecários estejam abertos para solucionar, de alguma forma, a problemática verificada neste estudo. 
Os professores da UFES devem passar da categoria de "usuários potenciais" à de "usuários reais" das bibliotecas. Isso certamente implicará o reconhecimento por parte dos professores de que as bibliotecas podem ser canais de comunicação possibilitadores do processo de apropriação e objetivação de conhecimento. Os bibliotecários por sua vez devem procurar detectar os fatores que possam estar influenciado na baixa freqüência dos professores às bibliotecas, para que embasados neles, e em conjunto com os professores, coloquem em prática ações concretas e efetivas, visando à reversão de um panorama há muito desenhado na Instituição.

Professores e bibliotecários, cientes das características da Sociedade da Informação, devem buscar a concretização de um projeto coletivo de formação continuada no qual a biblioteca seja incluída como um dos pilares da busca e recuperação da informação. Mais ainda, esse deveria ser pré-requisito de um trabalho interativo entre docentes e bibliotecários, visando à adoção de medidas que integrem as bibliotecas Central e Setoriais ao processo de formação continuada dos professores na UFES. Isso deve ser buscado porque, reconhecidamente, as bibliotecas universitárias são instituições responsáveis pela prestação de serviços informacionais. E, sendo assim, podem apoiar efetivamente as atividades de ensino, pesquisa e extensão desenvolvidas por professores, pesquisadores e alunos, não se limitando ao nível sistêmico organizacional na busca da informação e do conhecimento demandados por essas atividades (Tarapanoff et al., 1996).

Entretanto, para que essa função das bibliotecas universitárias se concretize, devemos continuar buscando maneiras de melhorar o seu desempenho, dentre as quais, com certeza, está a integração com a comunidade acadêmica. Para que isso ocorra, a biblioteca têm que sair de seu próprio "castelo" para ver o mundo de perto e questioná-lo junto à comunidade acadêmica. É preciso perguntar a essa comunidade se a biblioteca está atendendo ao que dela se espera (Vianna, 1996).

A literatura técnica produzida na área de Ciência da Informação e Biblioteconomia tem destacado problemas relacionados a planejamento, administração, recursos humanos, infra-estrutura e serviços, bem como outras dificuldades vivenciadas historicamente pelas bibliotecas universitárias, na mesma medida em que tem apontado soluções e modelos práticos de atuação. Todavia, são soluções que tratam dos problemas sem atingir o cerne dos mesmos: a complexa e dramática crise que assola as universidades brasileiras e, conseqüentemente, as bibliotecas universitárias, pois há que se considerar, que

“... falar das bibliotecas universitárias brasileiras é quase como falar da própria universidade [...]. Filosoficamente a biblioteca universitária é, em última análise, uma universidade em si mesma; assim como os enciclopedistas consideravam a 'Enciclopédia' como uma biblioteca impressa, a biblioteca universitária encerra, ou deveria encerrar, todo o saber da humanidade ela é [ou deveria ser] o locus da preparação de segmentos da sociedade. Imensurável e inesgotável é [ou deveria ser] o seu papel de ‘arquiteto silencioso' na construção do país que queremos, pois é lá que [devemos buscar a ampliação e clarificação do] nosso conhecimento. Com tamanha responsabilidade social e cultural, nada 
é mais necessário e urgente do que reconhecermos o seu próprio desempenho, a sua contribuição à sociedade" (Vianna, 1996, p. 3-4).

Por outro lado, é preciso reconhecer que na Sociedade do Conhecimento marcada pela globalização, pela grande produção e circulação de informações, promovidas em grande medida pelos avanços da telemática, seria duplamente ingênuo considerar somente as bibliotecas como canais de acesso à leitura e conceber as escolas e as universidades como únicos espaços de formação dos indivíduos. Num contexto em que os meios de comunicação da cultura humana duplicam-se a cada dia, em que surgem novos e variados espaços educacionais, devemos assinalar, isso sim, a necessidade de pensar/repensar a essência e a existência dessas instituições que foram historicamente sedimentadas na e pela sociedade. Isso deve ser feito com a intenção de fortalecer as suas dimensões social e cultural voltadas para humanização das relações sociais presentes e futuras.

Nesta direção, a utilização das novas tecnologias de informação podem ser aliadas importantes do processo de democratização da informação via canais tradicionais de disseminação de conhecimento, se tomadas como instrumentos do acesso ao novo mundo da leitura para a leitura/releitura do mundo pelo homem (Lajolo, 1997).

\section{REFERÊNCIAS BIBLIOGRÁFICAS}

BARBOSA, R. R. Acesso e necessidades de informação de profissionais brasileiros : um estudo exploratório. Perspectivas em Ciência da Informação, Belo Horizonte, v. 2, n. 1, p. 5-35, jan./jun. 1997.

CAVAlO, G., CHARTIER, R. História da leitura no mundo ocidental. 2. ed. São Paulo : Ática, 1998.

DUMANS, M. L. F. et al. Diagnóstico das necessidades e uso de informação téenico-científica entre os professores do Centro Pedagógico da UFES. Vitória : UFES/Departamento de Biblioteco-nomia, 1991. Relatório de pesquisa.

LAJOLO, M. Do mundo da leitura para a leitura do mundo. 3. ed. São Paulo : Ática, 1997.

PRAZERES, I. M. P. da. Busca da informação : comportamento dos docentes/ pesquisadores da Universidade Federal de Londrina. 1989. Dissertação (Mestrado em Biblioteconomia) - Pontifícia Universidade Católica de Campinas.

SILVA, E. T. da. Leitura na escola e na biblioteca. 5. ed. São Paulo : Papirus, 1995.

TARAPANOFF, K. et al. Biblioteca universitária e contexto acadêmico. In: SE-MINÁRIO NACIONAL DE BIBLIOTECAS UNIVERSITÁ-RIAS, 9., 1996, Curitiba. Anais... [disquete]. Curitiba : UFPR/Biblioteca Central, 1996. Doc. 4.3.

VIANNA, J. G. M. et al. A biblioteca e a sua relação com o contexto acadêmico. In: SEMINÁRIO NACIONAL DE BIBLIOTECAS UNI-VERSITÁRIAS, 9., 1996, Curitiba. Anais... [disquete]. Curitiba : UFPR/Biblioteca Central, 1996. Doc. 7.1. 